\title{
Empreendedorismo e consultoria informacional na área jurídica
}

\author{
Daniela Spudeit \\ Universidade do Estado de Santa Catarina, Departamento de Biblioteconomia e Gestão da Informação, \\ Florianópolis, SC, Brasil \\ danielaspudeit@gmail.com \\ Jackellynni Ferreira \\ Universidade Comunitária da Região de Chapecó, Biblioteca, Chapecó, SC, Brasil \\ jackellynniferreira@gmail.com
}

DOI: https://doi.org/10.26512/rici.v13.n2.2020.23030

Recebido/Recibido/Received: 2019-02-18

Aceitado/Aceptado/Accepted: 2020-03-22

Resumo: Este artigo analisa os serviços de informação na área jurídica para a prestação de consultoria por bibliotecários. Para isso, foram mapeados os profissionais que prestavam serviços de consultoria na área jurídica, foram identificadas as necessidades de informação na referida área e foram propostos serviços que podem ser ofertados por bibliotecários. Trata-se de uma pesquisa de caráter qualitativo, bibliográfico e descritivo. Para desenvolver este trabalho, foi aplicado um questionário com bibliotecários registrados no Conselho Regional de Biblioteconomia de Santa Catarina (14a região) que trabalham com informação jurídica em Florianópolis para que fosse possível mapear bibliotecários que prestassem serviços de consultoria na área jurídica, identificar necessidades de informação e propor serviços que possam ser ofertados na área jurídica. Conclui-se que inexistem bibliotecários trabalhando como consultores na área jurídica na cidade, dentre aqueles que foram localizados e aceitaram participar da pesquisa. Por outro lado, verificou-se que há muitos serviços que podem ser explorados nesse ramo tais como Disseminação Seletiva da Informação, serviço de referência, projetos internos e externos, programas e cursos de capacitação para a utilização de fontes de informação jurídica, dentre outros nichos. Também observou-se que durante a pesquisa a maioria dos bibliotecários que trabalha com a informação jurídica são servidores públicos, poucos trabalham no setor privado e nenhum presta serviços na área como consultor informacional de forma autônoma. Portanto, cabe ao bibliotecário se capacitar e conhecer as possibilidades existentes para acompanhar este nicho de atuação.

Palavras-chave: Biblioteconomia. Empreendedorismo. Consultoria. Informação Jurídica. Bibliotecário Jurídico. Serviços de informação. Santa Catarina (Estado).

\section{Entrepreneurship and informational consulting in the legal area}

Abstract: This article analyzes the information services in the legal area for the provision of advice consultancy by librarians. To this end, librarians were given legal consultancy services information needs were identified in the legal area and proposed services that can be offered by librarians in this area. This is a qualitative, bibliographic and descriptive research. To develop this work, a questionnaire was applied with librarians registered in the Regional Council of Librarianship of Santa Catarina (14th Region) who work with legal information in Florianopolis to be able to map librarians who provide legal services in the legal area, identify needs of information in the legal area and propose services that can be offered by librarians in the legal area. It is concluded that there are no librarians working in an entrepreneurial way 
as consultants in the legal area in the state, but it has been verified that there are many services that can be explored in the legal field such as Selective Dissemination of Information, Reference Service, internal projects and external, programs and training courses for the use of legal information sources, among other niches. It was also observed that during the survey most librarians working with legal information are public servants, few work in the private sector and none provide services in the area as an information consultant autonomously. Therefore, it is up to the librarian to be trained and to know the possibilities to accompany this niche

Keywords: Library Science. Entrepreneurship. Consulting. Legal Information. Law librarian. Information Services. Santa Catarina (State)

\section{Emprendimiento y consultoría informativa en el área legal}

Resumen: Este artículo analiza los servicios de información en el área legal para el asesoramiento de los bibliotecarios. Con este fin, los bibliotecarios recibieron servicios de consultoría legal, se identificaron las necesidades de información en el área legal y los servicios propuestos que pueden ofrecer los bibliotecarios en esta área. Esta es una investigación cualitativa, bibliográfica y descriptiva. Para desarrollar este trabajo, se aplicó un cuestionario a los bibliotecarios registrados en el Consejo Regional de Biblioteconomía de Santa Catarina (14a Región) que trabajan con información legal en Florianópolis para poder mapear a los profesionales que brindan servicios legales en el área legal, identificar las necesidades de información en el área legal y proponer servicios que pueden ofrecer los bibliotecarios en el área legal. Se concluye que no hay bibliotecarios que trabajen de manera empresarial como consultores en el área legal del estado, pero se ha verificado que existen muchos servicios que pueden explorarse en el campo legal, como la Difusión Selectiva de Información (DSI), Servicio de Referencia, proyectos internos y externos, programas y cursos de capacitación para el uso de fuentes de información legal, entre otros nichos. También se observó que durante la encuesta la mayoría de los bibliotecarios que trabajan con información legal son servidores públicos, pocos trabajan en el sector privado y ninguno proporciona servicios en el área como asesor de información de forma autónoma. Por lo tanto, depende del bibliotecario capacitarse y conocer las posibilidades de acompañar este nicho.

Palabras clave: Bibliotecología. Emprendimiento. Consultoría. Información legal. Bibliotecario Jurídico. Servicios de información. Santa Catarina (Estado).

\section{Introdução}

No século XX o mundo do trabalho passou por diversificadas alterações advindas da revolução industrial, da globalização e do desenvolvimento das tecnologias. Estes fenômenos oportunizaram a integração econômica entre os países, avanços nas formas de comunicação, no comércio e na tecnologia ampliando e mudando as formas de trabalho. Embora o empreendedorismo já existisse há muito tempo, foi somente no final do século XX e início do XXI que o conceito se tornou mais difundido no Brasil e no mundo. Para Dornelas (2008, p. 10):

O crescimento do empreendedorismo no mundo se acelerou na década de 1990 e aumentou em proporção nos anos 2000, o que pode ser observado nas ações desenvolvidas relacionadas ao tema. Alguns exemplos são: programas de incubação de empresas e parques tecnológicos; desenvolvimento de currículos integrados que estimulem o empreendedorismo em todos os níveis, da educação fundamental à pós-secundária; programas e incentivos 
governamentais para promover a inovação e a transferência de tecnologia; subsídios governamentais para criação e desenvolvimento de novas empresas; criação de agências de suporte ao empreendedorismo e à geração de negócios; programas de desburocratização e acesso ao crédito para pequenas empresas; desenvolvimento de instrumentos para fortalecer o reconhecimento da propriedade intelectual, entre outros.

Pode-se perceber que o investimento nas tecnologias, nas iniciativas e os subsídios governamentais, os estudos e o desenvolvimento de cursos contribuíram para a difusão do empreendedorismo no Brasil. Muitos profissionais de diferentes campos tiveram que se adaptar e passar por constantes atualizações para conseguir acompanhar as mudanças do mercado de trabalho, inclusive bibliotecários cujo principal insumo de trabalho é a informação. Para Moreira (2008, p. 45):

Uma reflexão sobre as grades curriculares dos cursos de Biblioteconomia surgiu ainda na década de 1990, quando houve o reconhecimento de que o objeto de estudo e trabalho do bibliotecário seria a informação, ainda que armazenada em diferentes suportes e espaços. Notou-se que o ambiente de trabalho do bibliotecário deveria ser toda e qualquer unidade de informação, e não apenas as bibliotecas. Novos campos de atuação começaram a se tornar mais comuns aos bibliotecários e, consequentemente, um novo perfil profissional começou a ser desenhado.

Na década de 1990, Marchiori (1996, p. 31) acompanhava este momento de mudança, e apoiava um novo perfil de profissional em que "[...]o bibliotecário não fosse mais um obscuro num canto de quatro paredes, mas um empreendedor e amante da visibilidade".

O bibliotecário precisa ser visionário, buscar novas linhas de atuação, se especializar para que consiga exercer funções nas quais demandam práticas ainda não vivenciadas e aprendidas para que possa identificar novos nichos dentro da gestão da informação além dos tradicionais espaços em bibliotecas como em hospitais, escritórios, empresas em geral para posteriormente, empreender, ser dono do seu próprio negócio. Contudo, esta visão do empreendedorismo ainda é recente para a Biblioteconomia, pois exige capacitações constantes para atender as demandas específicas do mercado no que tange à prestação de serviços na área de informação.

Este profissional deve procurar adquirir competências para que consiga empreender, como ressaltam Cardozo e Barbosa (2004, p. 17) “[...] o bibliotecário-empreendedor deve ser criativo, flexível, inovador e ter visão do negócio em que atua, além de estar sempre sensibilizado para a necessidade de atualização permanente, no que tange ao conhecimento e às técnicas e métodos de trabalho". 
Esta mudança de perfil está atrelada ao vasto campo no qual este profissional pode vir a desempenhar diferentes atividades. Umas das oportunidades que vem se consolidando no ramo de atuação para o bibliotecário é o da consultoria onde este profissional tem mais autonomia, empreende e se especializa em diversificados campos do conhecimento para que possa prestar este serviço. Oliveira $(1999$, p. 19) conceitua consultoria como "[...] um processo interativo de um agente de mudança externo à empresa, o qual assume a responsabilidade de auxiliar os executivos e profissionais da referida empresa nas tomadas de decisões, não tendo o controle direto da situação." O bibliotecário então, pode atuar neste segmento, transformando a informação em conhecimento como afirmam Milano e Davok (2009, p. 254):

O bibliotecário surge nesse segmento prestando serviços de Consultoria Informacional em sua área de formação e auxiliando na transformação da informação em conhecimento. Como gestor da informação, ele sabe que a informação é a matéria prima do conhecimento, podendo assim atuar de forma direta ou indireta nas organizações. Nessa direção, é importante conhecer a atuação desse profissional na área de consultoria, para que os serviços prestados possam ser completados e aperfeiçoados.

Valentim (2000) apresenta diferentes nichos para o bibliotecário atuar e empreender tais como: indústria, área da saúde, bancos e finanças, contabilidade, empresas, no meio jurídico, entre outros. A autora caracteriza como mercado informacional tradicional, mercado informacional existente não ocupado e o mercado informacional - tendências.

Entre outras áreas, no âmbito jurídico existem demandas para o bibliotecário atuar como consultor na área de informação visto que há um grande volume de informações sendo produzidas por meio das normas legislativas, da produção científica, publicações de livros, teses e artigos que podem servir como subsídio para o trabalho de profissionais da área de Direito. Passos (2001, p. 1) explica que "a especialidade do bibliotecário jurídico é conhecer as fontes de informação jurídicas e realizar pesquisas na área do Direito". Portanto, advogados, juízes, estudantes, pessoas com necessidades específicas na área jurídica e professores precisam de informação com presteza e qualidade para fundamentar suas decisões e o bibliotecário pode prestar este serviço com maestria. Dessa forma, traçou-se como questão norteadora da pesquisa: Quais os tipos de serviços informacionais podem ser oferecidos por bibliotecários para atender aos profissionais da área jurídica?

Para responder a isso, o objetivo geral foi levantar serviços de informação na área jurídica que podem, potencialmente, ser prestados, por meio de consultoria, por bibliotecários. Para isso, elencaram-se como objetivos específicos: a) Mapear, a partir do cadastro no Conselho Regional de Biblioteconomia e Associação Catarinense de Bibliotecários, os bibliotecários que prestem serviços de consultoria na área jurídica; b) Identificar necessidades de informação na 
área jurídica segundo os bibliotecários que atuam nessa área; c) Verificar serviços que são oferecidos por bibliotecários que atuam na área jurídica.

Após a realização dessa pesquisa, foi possível propor outros serviços que podem ser ofertados por meio de consultoria por bibliotecários na área jurídica.

Esta pesquisa pretende contribuir para que o bibliotecário enxergue novos campos de atuação e contribua com serviços que possam agregar valor na atuação dos profissionais da área de Direito. Passos e Barros (2009) apresentavam que havia um aumento grande em publicações legislativas, como normas e jurisprudências, pesquisas oriundas da produção dos cursos de graduação e pós-graduação que contribuíram para o desenvolvimento da ciência jurídica, com a publicação de livros, teses, artigos. Atualmente, nada mudou. Miranda e Miranda (2017) destacam a rapidez da renovação da quantidade de fontes de informação jurídica, ressaltando a legislação, jurisprudência e doutrina.

Analisando este contexto, advogados, professores e juízes precisam de um profissional qualificado que saiba fazer a organização, seleção, tratamento e armazenamento destas informações para que, posteriormente, isso possa ser recuperado. O bibliotecário passa a ser 0 intermediário entre a informação segura e com presteza para os profissionais do âmbito jurídico. Como afirma Aguiar Júnior ${ }^{1}$ "[...] se esse auxílio era dispensável no passado, pelas próprias condições do trabalho, hoje é absolutamente inviável que o operador do direito atue sem contar com a colaboração do bibliotecário, por mais simples que seja a sua tarefa".

Além disso, esta pesquisa contribui para a área da Biblioteconomia no sentido de servir de fonte de referência para os bibliotecários que trabalham com informação jurídica, bem como para os profissionais que têm interesse em atuar como consultores nessa área visto a demanda que existe por informações especializadas sobre Direito e legislações.

\section{Fundamentação teórica}

Empreendedorismo é uma temática bem aprofundada na área da Administração em que vários autores como Filion (1999), Dornelas (2008), Hisrish, Peters e Shepherd (2009) entre outros, apresentam estudos sobre sua evolução, histórico e importância no mundo. Para Dornelas (2008), na Idade Média, o empreendedor era considerado um gerenciador de grandes projetos de produção. Neste período, o empreendedor não assumia grandes riscos e, em seus projetos, eram utilizados os recursos disponíveis, geralmente financiados pelo governo.

\footnotetext{
1 Prefácio feito pelo ex ministro do Supremo Tribunal de Justiça (STJ) no livro da Passos e Barros (2009, p. 8).
} 
No século XVII, o termo empreendedor começou a ter um sentido mais concreto, o empreendedor assumia riscos, visto que os preços dos produtos eram prefixados, então os prejuízos e os lucros ficavam por conta dele. Richard Cantillon (escritor e economista do século XVII) foi, segundo Dornelas (2008, p. 14), “[...] um dos primeiros a diferenciar o empreendedor - aquele que assumia riscos -, do capitalista - aquele que fornecia o capital".

No século XVII as mudanças de paradigmas nas formas de trabalho advindos da revolução industrial influenciaram diretamente na economia e nas formas de empreender. Neste contexto, as bases tradicionais de trabalho que anteriormente se dava pela agricultura e o artesanato, foram substituídas pelo trabalho fabril. O comportamento empresarial após a Revolução Industrial contribuiu com o surgimento das empresas "modernas", criando um vínculo entre a demanda tecnológica e os objetivos lucrativos. Para Schumpeter (1928 apud FILION, 1999, p. 7):

A essência do empreendedorismo está na percepção e no aproveitamento das novas oportunidades no âmbito dos negócios [...] sempre tem a ver com criar uma nova forma de uso dos recursos nacionais, em que eles sejam deslocados de um emprego tradicional e sujeitos a novas combinações.

Pode-se identificar, nas palavras de Joseph Schumpeter, uma percepção contemporânea e também a importância do empreendedorismo para o contexto econômico. Ele vislumbrava que as oportunidades deveriam ser aproveitadas e que os recursos já existentes deveriam ser aprimorados para novas formas de uso.

Os fatores sociais, políticos e econômicos do século XX influenciaram diretamente na mudança de paradigma no mundo do trabalho. A Revolução Industrial, os estudos e pesquisas feitos do modo de produção, as guerras civis, políticas e religiosas, a globalização e a tecnologia atuaram para que houvesse a modificação e a evolução do trabalho. Para acompanhar estas mudanças, é necessário que as organizações e profissionais promovam sua capacitação, adaptação e atualização para seguir os novos moldes impostos. (CONTI; PINTO; DAVOK, 2009).

Pode-se caracterizar o empreendedor como uma pessoa inovadora, criativa, que identifica e se aproveita das oportunidades, assume riscos, possui foco, tem a capacidade de organizar e planejar, o que o auxilia a ter uma visão estratégica sobre seu negócio ou serviço (DOLABELA, 2008; SABBAG, 2013). Para que sejam formadas as competências, o empreendedor deve ter certos conhecimentos e habilidades que são atribuídos ao seu perfil. Dolabela (2008, p. 28) destaca as características do perfil empreendedor:

O empreendedor é um ser social, produto do meio em que vive (época e lugar). Se uma pessoa vive em um ambiente em que ser empreendedor é visto como algo positivo, terá motivação para criar seu próprio negócio. [...] É um fenômeno local, ou seja, existem cidades 
regiões, países mais - ou menos - empreendedores do que os outros. O perfil do empreendedor (fatores do comportamento e atitudes que contribuem para o sucesso) pode variar de um lugar para o outro.

Para Drucker (1986, p. 36) o empreendedor "[...] vê a mudança como norma e como sendo sadia". As formas praticadas para as mudanças geralmente são enxergadas pelo empreendedor como um aprendizado que o fortalece e aumenta seus conhecimentos e o incentiva a inovar e buscar novas oportunidades.

Na Biblioteconomia, foi a partir da década de 1990 que foram criadas as primeiras empresas formalizadas, conforme explica Spudeit (2016a). A autora afirma que a maioria dos bibliotecários ainda atua nos espaços tradicionais e não vislumbram que os serviços prestados por estes profissionais, nestes ambientes, podem ser aproveitados também para a abertura do seu próprio negócio.

Embora seja um movimento recente, no Brasil existem empresas fundadas por bibliotecários conforme pesquisa de Spudeit et al. (2016b). Nesse estudo, observa-se que existem muitos campos de atuação para o bibliotecário empreender como na organização de bibliotecas, gestão de documentos eletrônicos, gestão de projetos, treinamentos e capacitação na área de informação, entre outros. Na mesma linha, o Conselho Regional de Biblioteconomia da 14a Região (CRB14, 2016, grifo nosso) enfatiza que:

O bibliotecário está habilitado a executar: Planejamento de serviços biblioteconômicos; Planejamento físico de bibliotecas, centros de documentação e informação; Organização de acervos (bibliográficos ou não); Serviços técnicos e administrativos ligados à documentação; Assessoria, consultoria, ensino, fiscalização técnica, normalização de documentos, análise de trabalhos técnicos e científicos; Organização de bases de dados virtuais e intranets; Documentação para processos de certificação de qualidade; Avaliação de conteúdo da Internet, entre outras.

Pode-se afirmar que o insumo de trabalho do bibliotecário é a informação, independente do suporte em que a informação esteja registrada. Portanto, a consultoria informacional é uma das áreas em que o bibliotecário pode empreender. Sendo a informação ferramenta chave de trabalho para os bibliotecários é importante que ela seja examinada e, posteriormente, tratada para que se repasse um conhecimento de qualidade para seu contratante. Torna-se, então, relevante que o bibliotecário se capacite para entender melhor sobre a área em que irá prestar o serviço como consultor (MILANO; DAVOK, 2009).

No caso da atuação do bibliotecário como consultor informacional deve usar de aprendizados e ferramentas adquiridos na sua formação. Contudo, ele deve se qualificar e estar em constante atualização para que consiga suprir a demanda informacional de seu contratante. A informação é um 
fator primordial para a tomada decisão nas organizações. Por isso, o consultor informacional trabalha com seu intelecto, avaliando os problemas impostos por seu interagente cuidadosamente, para depois expor as melhorias que possam vir a auxiliá-lo.

Segundo a Resolução no 42/2002 do Conselho Federal de Biblioteconomia "Art. 10 Quando consultor, é responsabilidade do Bibliotecário apresentar métodos e técnicas compatíveis com o trabalho oferecido, objetivando o controle da qualidade e a excelência de prestação de serviços durante a após a execução dos trabalhos". (CONSELHO..., 2002, p. 2)

O bibliotecário pode empreender em diversas áreas conforme demonstra a Association of Independent Information Professionals (2016): indústria e negócios, pesquisa jurídica, saúde, bancos e finanças, poder público, ciência e tecnologia, bem como document delivery ${ }^{2}$.

Na pesquisa jurídica, o bibliotecário pode atuar realizando levantamentos bibliográficos, organização de acervos, serviços de alerta, gestão documental e uma infinidade de serviços. Entretanto, para se especializar no ramo de consultoria jurídica, é necessário conhecer primeiramente as fontes de informação especializadas. Na área do Direito, Passos e Barros (2009, p. 122) salientam que "[...] as fontes de informação jurídica podem ser representadas por pessoas, instituições, empresas, cartórios, obras de referência, serviços e sistemas de informação, bases de dados, etc., podendo estar fisicamente presentes ou não na biblioteca".

Há um vasto campo informacional para ser pesquisado, contudo é necessário tomar por verdade que a área do Direito está alinhada a três tipos principais de fontes de informação: a doutrina, a legislação e a jurisprudência. É por meio destas fontes que o bibliotecário jurídico presta serviços de consultoria e obtém a informação de forma sucinta e presta serviços para pessoas do âmbito jurídico. Sendo assim, Barros (2004, p. 203) dá uma definição sobre esses três tipos de fontes de informação jurídica:

Doutrina: é definida como a interpretação de autores, juristas e escritores acerca de uma norma ou decisão jurídica. Legislação: é o conjunto de diplomas legais ou disposições emanadas de autoridades em seus diversos níveis de atuação. Jurisprudência: é como fonte secundária do Direito, consiste no conjunto de decisões reiteradas de juízes e tribunais sobre determina tese jurídicos.

Também existem outras fontes que servem de apoio para a busca da informação jurídica de qualidade conforme levantamento, constante no quadro 1, feito por Passos e Barros (2009):

\footnotetext{
${ }^{2} \mathrm{NA}$ : Entrega de Documentos.
} 
Quadro 1- Fontes de Informação Jurídica

\begin{tabular}{|c|c|}
\hline CATEGORIA & FONTE \\
\hline $\begin{array}{l}\text { Fontes } \\
\text { primárias }\end{array}$ & Diário Oficial da União; Diários oficiais dos estados e Diário da Justiça. \\
\hline $\begin{array}{l}\text { Fontes } \\
\text { secundárias }\end{array}$ & $\begin{array}{l}\text { Livros jurídicos; Cartilhas e apostilas; Periódicos jurídicos: Revista Forense (RF); Revista } \\
\text { Jurídica (RJ); Revista dos Tribunais (RT); Periódicos eletrônicos: Jus Navegandi - é } \\
\text { reconhecido pelo Instituto Brasileiro de Informação em Ciência e Tecnologia (IBICT) como } \\
\text { publicação periódica em linha com o International Standard Serial Number (ISSN) 1518- } \\
\text { 4862; Teses jurídicas; Biblioteca Digital de Teses e Dissertações (BDTD); Dicionários: } \\
\text { Vocabulário Jurídico; Enciclopédias: Repertório Enciclopédico do Direito Brasileiro; } \\
\text { Enciclopédia Saraiva do Direito; Vade-mécuns; Coleções de leis e Coleções de } \\
\text { jurisprudência. }\end{array}$ \\
\hline $\begin{array}{l}\text { Sistemas e } \\
\text { bases de dados }\end{array}$ & $\begin{array}{l}\text { Bases de dados de legislação federal de hierarquia superior; Sistema de Informações do } \\
\text { Congresso Nacional (SICON). Legislação Federal do Brasil - mantida pela Presidência da } \\
\text { República; Congresso Brasileiro de Biblioteconomia, Documento e Ciência da Informação; } \\
\text { Sistema de Legislação Informatizada (LEGIN) - mantido pela Câmara dos Deputados; Bases } \\
\text { de dados de legislação estadual e distrital; Bases de dados de jurisprudência; Bacen-Jud; } \\
\text { Bases de dados estrangeiras }\end{array}$ \\
\hline Bibliotecas & $\begin{array}{l}\text { Biblioteca do Senado Federal; Biblioteca da Câmara dos Deputados; Biblioteca dos } \\
\text { tribunais; Bibliotecas universitárias; Bibliotecas virtuais e Biblioteca Digital Jurídica }\end{array}$ \\
\hline Internet & Sites jurídicos \\
\hline $\begin{array}{l}\text { Instituições } \\
\text { públicas como } \\
\text { fontes de } \\
\text { informação } \\
\text { jurídica }\end{array}$ & $\begin{array}{l}\text { O Poder Legislativo; Congresso Nacional; Câmara dos Deputados; Senado Federal; O Poder } \\
\text { Executivo; Presidência da República, secretarias, ministérios, departamentos, conselhos, } \\
\text { superintendências, autarquias, sociedades de economia mista, empresas públicas, } \\
\text { fundações, universidades etc.; Imprensa Nacional; O Poder Judiciário; o Supremo } \\
\text { Tribunal Federal; Superior Tribunal de Justiça; Justiça Federal; Justiça do Trabalho; Justiça } \\
\text { Militar; Órgãos essenciais à Justiça; Ministério Público; Advocacia-Geral da União; } \\
\text { Advocacia e Defensoria Pública }\end{array}$ \\
\hline $\begin{array}{l}\text { Organizações } \\
\text { como fontes de } \\
\text { informação }\end{array}$ & $\begin{array}{l}\text { Livrarias e Editoras; Cartórios; Escritórios de advocacia; Associações de classe; } \\
\text { Universidades e Anuário da advocacia. }\end{array}$ \\
\hline $\begin{array}{l}\text { Grupos de } \\
\text { Documentação } \\
\text { Jurídico }\end{array}$ & $\begin{array}{l}\text { Infolegis e Grupo de Profissionais em Informação e Documentação Jurídica do Rio de } \\
\text { Janeiro (GIDJ/RJ) }\end{array}$ \\
\hline $\begin{array}{l}\text { Eventos } \\
\text { científicos }\end{array}$ & Jurídica (ENIDJ). \\
\hline
\end{tabular}

Fonte: Passos e Barros (2009, p. 131)

Por conta deste grande volume informacional, gerado a partir das fontes citadas por Passos e Barros (2009), o trabalho do bibliotecário é essencial, para que a informação receba o tratamento adequado e, posteriormente, seja recuperada.

Em uma pesquisa na literatura, foram encontradas algumas iniciativas e grupos profissionais no Brasil que fazem o trabalho intermediário da informação jurídica para os bibliotecários interessados: Infolegis, Grupos de Bibliotecários em Informação e Documentação Jurídica (GIDJ); Grupo de Informação e Documentação Jurídica de São Paulo (GIDJ/SP); Grupo de Bibliotecários em Informação e Documentação Jurídica (GBIDJ/SC) e Grupo de Trabalho em 
Documentação Jurídica da Associação Rio-Grandense de Bibliotecários. O único grupo que se encontra inativo é o Grupo de Bibliotecários em Informação e Documentação Jurídica (GBIDJ/SC), que é vinculado à Associação Catarinense de Bibliotecários. No Distrito Federal, a Associação dos Bibliotecários e Profissionais da Ciência da Informação do Distrito Federal (ABDF) reativou o Grupo de Informação e Documentação Jurídica do Distrito Federal (GIDJ) em $2018^{3}$.

Silva $(2005$, p. 23) cita que "[...] com o surgimento da internet, órgãos produtores de informação jurídica passaram a disponibilizar informações mais rapidamente através de sites próprios, como os Tribunais, Ministérios Públicos, Senado Federal [...] entre outros". Dessa forma, percebe-se que as fontes de informação on-line auxiliam os bibliotecários que trabalham no âmbito jurídico, visto que existem muitos sites atualizados que possuem conteúdo da área disponível na internet de forma gratuita conforme Silva (2005).

Como as leis, jurisprudências e doutrinas estão em constante atualização e passam por rápidas mudanças, as fontes impressas não conseguem acompanhar a produção da área, tornando assim a internet uma das fontes mais utilizadas para recuperar a informação atualizada.

\section{Procedimentos metodológicos}

A pesquisa tem como principal finalidade proporcionar soluções para a problemática e para os objetivos a serem investigados por meio da análise dos serviços de informação na área jurídica para a prestação de consultoria por bibliotecários. Para isso, foram mapeados os profissionais que prestavam serviços de consultoria na área jurídica, foram identificadas as necessidades de informação na referida área e foram propostos serviços que podem ser ofertados.

Caracteriza-se como uma pesquisa qualitativa, bibliográfica e descritiva. Para atingir os objetivos, mapearam-se os bibliotecários que atuavam na área jurídica (seja como funcionários em instituições ou como consultores) em Florianópolis via contato com Conselho Regional de Biblioteconomia (CRB) da 14a região e Associação Catarinense de Bibliotecário (ACB).

De acordo com o Conselho Regional da 10a Região em uma pesquisa feita em $2013^{4}$, existiam 1387 bibliotecários inscritos em Santa Catarina, sendo 801 ativos. Porém, para a pesquisa foi enviado o questionário somente para bibliotecários da cidade de Florianópolis.

\footnotetext{
${ }^{3}$ Disponível em http://abdf.org.br/gidj/

${ }^{4}$ Disponivel em: http://crb10.blogspot.com.br/2013/07/total-de-bibliotecarios-nobrasil.html?utm source=twitterfeed\&utm medium=facebook
} 
Após envio da solicitação via ACB e CRB14, identificaram-se 18 (dezoito) bibliotecários que trabalham no setor público e privado no meio jurídico e todos aceitaram participar da pesquisa. Os dados foram demonstrados por meio de gráficos e as questões abertas foram transcritas com as devidas considerações discutidas com base na literatura. Para facilitar a comparação, foi utilizado um código-chave B1, B2 e assim por diante para a identificação dos bibliotecários e preservar o anonimato.

Para a coleta de dados, utilizou-se como instrumento de pesquisa o questionário elaborado na plataforma Survey Monkey ${ }^{5}$ que foi enviado por e-mail. A partir disso, foi possível traçar um perfil destes profissionais, verificar a qualificação, as fontes de informação que usam, as dificuldades encontradas na busca da informação, serviços que podem ser oferecidos na área jurídica, entre outras percepções que serão apresentadas a seguir.

\section{Apresentação e discussão dos dados}

Nesta seção são discutidos os dados das respostas dos bibliotecários que aceitaram participar da pesquisa e atuam na área jurídica na cidade de Florianópolis, Santa Catarina. Como forma de facilitar a análise dos dados, o conteúdo recolhido foi subdivido em sete categorias: faixa etária, tempo de atuação na área jurídica e especialização e cursos de qualificação, forma de contratação, uso de fontes de informação, as dificuldades na busca por informação jurídica, tipos de serviços desenvolvidos, contribuição do bibliotecário para o ambiente jurídico e as principais necessidades de informação do público atendido por estes profissionais.

\subsection{Faixa etária, tempo de atuação e formação}

A primeira pergunta do questionário buscou identificar a faixa etária dos bibliotecários:

\section{Gráfico 1- Faixa etária}

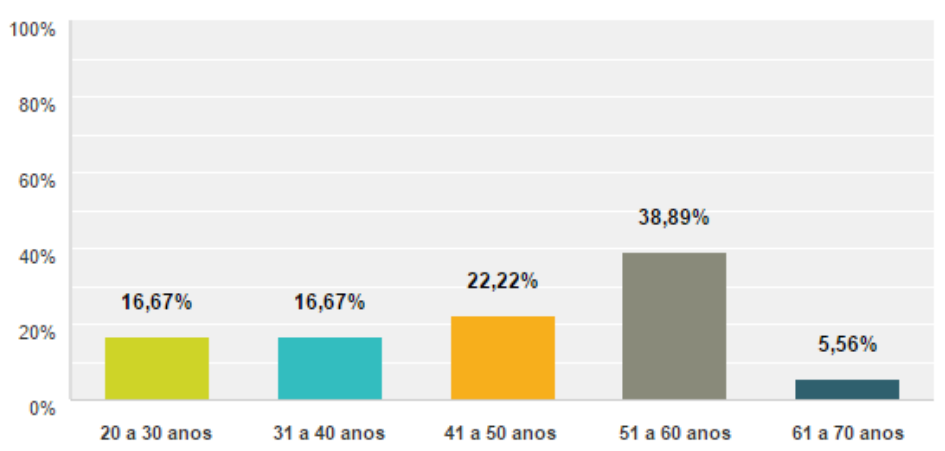

Fonte: Dados da pesquisa (2016)

\footnotetext{
${ }^{5}$ Disponível em https://pt.surveymonkey.com/?
} 
Verifica-se que, em sua maioria, os bibliotecários possuem idade superior a 50 anos de idade e que a segunda maior faixa etária é de 41 a 50 anos, o que evidencia um relativo nível de maturidade destes especialistas. Vislumbrou-se também compreender o tempo de atuação destes profissionais na área jurídica como mostra o Gráfico 2:

Gráfico 2 - Tempo de atuação na área jurídica

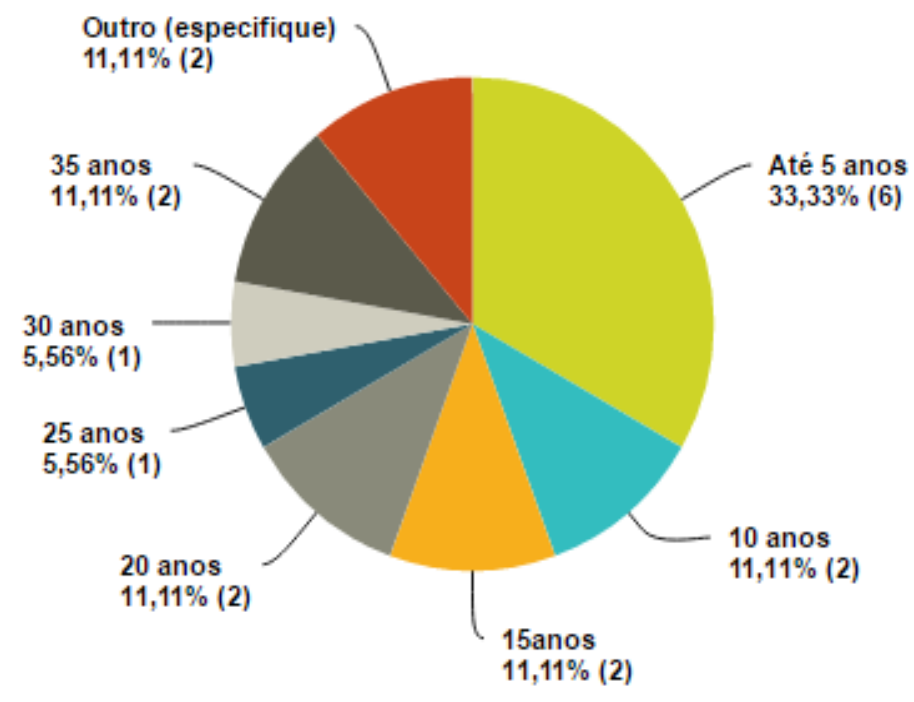

Fonte: Dados da pesquisa (2016).

Analisando o gráfico, é possível verificar que 33\% dos bibliotecários atua na área jurídica há apenas cinco anos, o restante está bem dividido entre as demais opções. Pode-se observar que apesar dos bibliotecários jurídicos terem a idade superior a 50 (cinquenta) anos o seu tempo de atuação na área é de até 5 anos em sua maioria, o que pode indicar que estes profissionais iniciaram a graduação não tão jovens ou que sua atuação no ramo, foi tardia.

A questão seguinte discorreu sobre a especialização e a qualificação dos entrevistados na área jurídica, sete responderam que "não possuem" formação específica nesta área. Baptista et al. (2008, p. 14) explicam que "No caso específico do bibliotecário jurídico brasileiro, a educação continuada não pode ser buscada nos bancos das universidades, porque não existe nenhum curso de especialização nessa área".

Alguns bibliotecários fizeram cursos na área do Direito: o bibliotecário B1 respondeu que "sim, mas não me recordo no momento os nomes deles", para o B3 "DIREITO E PROCESSO DO TRABALHO", já o B12 "sim Direito incompleto" e o B16 "Bacharel em direito". Um bibliotecário que atua na área jurídica deve se especializar nessa área para facilitar o diálogo com esses profissionais (assessores jurídicos, advogados, juízes, etc.) e também efetivar seu 
fazer profissional. Mourão (2009) alerta que educação e trabalho são conceitos interrelacionados, quanto melhor qualificado melhor sua atuação profissional. Ela cita que é preciso ampliar as oportunidades de qualificação profissional para garantir a produtividade e competitividade, permitir autonomia e autovalorização da mão-de-obra e para a própria sobrevivência e a qualidade e produtividade das empresas.

Nota-se, também, que alguns dos bibliotecários responderam que fizeram cursos relacionados à área "CURSOS DE CURTA DURAÇÃO” (B2) “Durante a carreira, fiz vários cursos na área, normalmente de pequena duração. Alguns foram patrocinados pela instituição e outros foram de iniciativa particular (B14).

Mendes (2010, p. 1) explica que "[...] é necessário um conhecimento específico sobre as ferramentas, fontes de informação e atividades que cabem ao bibliotecário". Por conta disto, é importante que se qualifiquem e busquem conhecimentos de diferentes formas, seja por meio de cursos e especializações, estudos individuais, capacitações específicas no próprio local de trabalho, entre outros

Contudo, alguns bibliotecários ressaltam que fizeram especializações em outras áreas "Especialização em Políticas Públicas" (B4), "Na área jurídica não, tenho 2 pós na área administrativa e empresarial” (B10), "Na área jurídica não, no entanto, tenho 2 especializações e mestrado, todas em gestão" (B13).

Apesar de sete bibliotecários responderem que não possuem nenhum tipo de qualificação na área, a pesquisa mostra que os profissionais estão buscando se qualificar seja por meio de cursos, especializações (não exatamente na área do Direito) e até mesmo uma segunda graduação. É positivo ver que estes bibliotecários estão se mantendo atualizados e dando continuidade extensivamente para ser tornarem profissionais mais capacitados.

\subsection{Formas de contratação}

Segundo Passos e Barros (2009, p. 106) o bibliotecário jurídico pode atuar em "[...] bibliotecas jurídicas, universidades, [...] órgãos governamentais e [...] escritórios de advocacia". Na questão que aborda as formas de contratação, visualiza-se que $72,22 \%$ dos bibliotecários estão atuando no serviço público, $27,78 \%$ estão no setor privado e nenhum trabalha como autônomo.

Baptista (1998) estudou o fenômeno comparando aqueles que trabalhavam de forma autônoma, em relação àqueles que são vinculados a alguma instituição. Em sua tese, publicada a mais de vinte anos, a autora apresentou alguns indícios sobre os motivos do surgimento de um mercado alternativo para os bibliotecários, as características da atuação e do mercado como autônomos, em comparação com os institucionalizados. Baptista afirmou que (1998, p. 221): 
Foi possível observar a visão dos autônomos diferenciada dos institucionalizados quanto ao fator estabilidade como motivo de escolha pela instituição, na discordância em relação aos institucionalizados de que o contrato assegura a estabilidade e nas discordâncias sobre a inexistência de um sistema justo de pagamento (relacionamento com a organização) e na preferência pela inovação (organização ideal).

Dessa forma, percebe-se que no mercado informacional pouco mudou de 1998 a 2018 no que tange aos motivos que levam o bibliotecário a empreender sendo a estabilidade e remuneração fixa os principais fatores que atraem os profissionais para empresas privadas ou órgãos públicos.

Gráfico 3 - Formas de contratação.

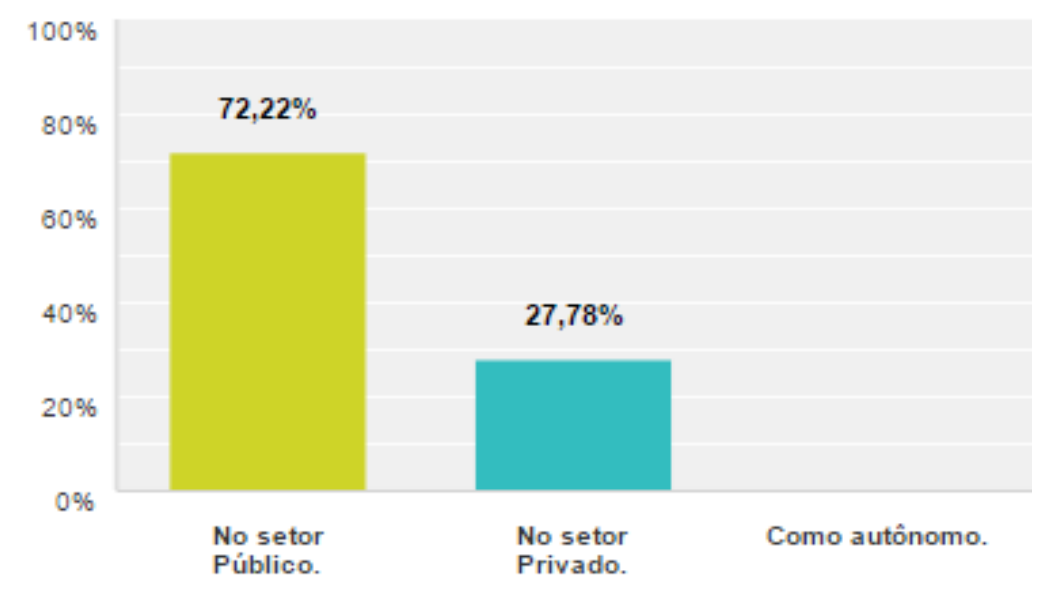

Fonte: Dados da pesquisa (2016).

Nota-se que o bibliotecário que segue por este ramo está mais direcionado ao setor público. Para Rachel (2008, p. 1) o serviço público pode ser definido como: “[...] uma utilidade ou comodidade material fruível [sic] singularmente, mas que satisfaz necessidades coletivas que o Estado assume como tarefa sua, podendo prestar de forma direta ou indireta, seguindo regime jurídico de direito público total ou parcial".

Em Florianópolis, a atuação no setor público ocorre na Assembleia Legislativa do Estado de Santa Catarina, Justiça Federal de Santa Catarina, Ministério Público Estadual, Ministério Público Federal, Ordem dos Advogados do Brasil, Procuradoria da República de Santa Catarina, Procuradoria Geral do Município, Tribunal de Contas de Santa Catarina, Tribunal de Justiça de Santa Catarina, Tribunal Regional Federal da 4a Região e Tribunal Regional do Trabalho. Verifica-se que $27,78 \%$ atuam no setor privado, o que demonstra que as competências do bibliotecário ainda são pouco reconhecidas pelos potenciais empregadores 
neste meio, pode apenas concluir que o emprego público absorve mais bibliotecários que o privado.

\subsection{Uso de fontes de informação}

As fontes de informação são a base do trabalho do bibliotecário visto que é por meio delas que são supridas as demandas de informação das pessoas que buscam saciar suas necessidades informacionais. Na questão que tange o uso de fontes de informação foi feita uma classificação numérica ( 1 para mais utilizada e 3 para a menos utilizada) como forma de elencar as principais fontes que estão sendo utilizadas por bibliotecários que trabalham no ramo jurídico, como demonstra o Gráfico 4:

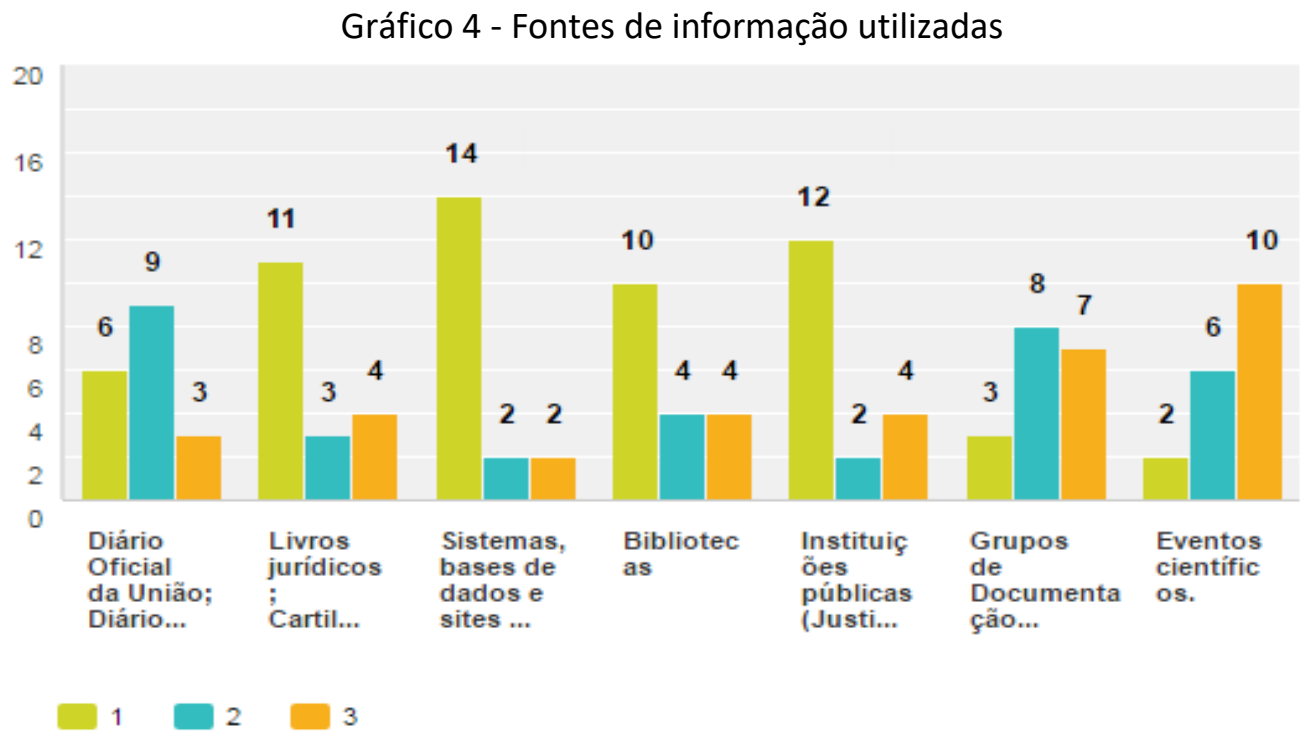

Fonte: Dados da pesquisa (2016).

Passos e Barros (2009) apresentam as principais fontes da pesquisa em Direito que são os sistemas e bases de dados, bibliotecas, internet, instituições públicas como fontes de informação jurídica, organizações como fontes de informação, grupos de documentação jurídica e os eventos científicos. Na pesquisa, verifica-se que a fonte mais utilizada por estes bibliotecários são sistemas, bases de dados e sites da Internet em que $77,88 \%$ responderam que essas são as mais usadas. Para Passos $(2015$, p. 2):

As fontes disponíveis na Internet têm grandes vantagens: podem ser acessadas em qualquer lugar e em qualquer hora; são gratuitas, portanto não geram custo adicional para aqueles que a pretendem utilizar; geralmente seus pontos de acesso são comuns e os instrumentos de busca são amigáveis; entre outras vantagens. 
Para estes profissionais da área jurídica é mais vantajoso utilizar a internet como uma fonte, visto que a informação jurídica é algo que muda com muita frequência, o que torna quase impossível os livros impressos acompanharem tais modificações. Contudo, os livros alcançaram cerca de $61,11 \%$ na escala, o que demonstra que este suporte informacional ainda é bastante utilizado pelos profissionais da área jurídica.

Em segundo lugar, verifica-se que a fonte mais indicada com $66,67 \%$ são as Instituições Públicas, na quais Barros (2004, p. 203) mapeia como sendo:

O Poder Legislativo (Congresso Nacional, Câmara dos Deputados e Senado Federal); O Poder Executivo; Presidência da República, secretarias, ministérios, departamentos, conselhos, superintendências, autarquias, sociedades de economia mista, empresas públicas, fundações, universidades etc.; Imprensa O Poder Judiciário (Supremo Tribunal Federal, Superior Tribunal de Justiça, Justiça Federal, Justiça do Trabalho, Justiça Militar, Órgãos essenciais à Justiça etc.

Verifica-se que os eventos científicos obtiveram cerca de 55,56\% na escala de nível 3 (três) de menos utilizados, juntamente com os grupos de documentação que receberam 38,89\%. Estes dados podem ser diretamente relacionados com o Grupo de Bibliotecários em Informação e Documentação Jurídica (GBIDJ/SC) que não está ativo, o que que implica na produção direta e no interesse de resgatar os eventos científicos da área jurídica para a região de Florianópolis.

Seria necessário que os bibliotecários jurídicos se organizassem e reativassem o GBIDJ/SC, visto que, conforme afirmado anteriormente, esses grupos propõem discussão, distribuição de conteúdo, cursos e outras atividades, além de servirem como fonte de informação para outros profissionais que se interessem por esta área.

\subsection{Dificuldades na busca por informação jurídica}

Os bibliotecários que trabalham com informação jurídica, ao serem questionados sobre as dificuldades na busca por informação na área, explicam que um grande problema encontrado é a "DESATUALIZAÇÃO” (B6, B14).

Para Perillo (2012, p. 17) "O volume de informação jurídica aumenta rapidamente, diante da constante atualização da legislação, alterando todo o sistema jurídico." Cabe, então, ao bibliotecário ficar atento ao surgimento de novas leis, assim como nas alterações das já vigentes.

Outro ponto citado que vale realçar, além da atualização dos conteúdos seria a indexação. O maior problema, como afirma o respondente B4, são os "mecanismos de busca; indexações inadequadas; atualizações" (B4). Já para o B17 falta o tratamento adequado para que seja possível recuperar a informação com mais facilidade. "Acho que o tratamento da recuperação da informação, em algumas fontes essa recuperação fica truncada" (B17). Contudo, 
o respondente B13 acha que "Muitas vezes o usuário nos procura com temas abrangentes e a dificuldade é a especificidade" (B13).

Dessa forma, pode-se enumerar como dificuldades quanto ao acesso e uso da informação, para este grupo de pesquisa: a) desatualização; b) volume c) recuperação d) especificidade. Para atender essas demandas e sanar essas dificuldades, Passos (2001, p. 2) aponta que "O bibliotecário jurídico é o profissional que facilita o acesso à informação jurídica de forma ágil e eficiente". Assim, o bibliotecário que trabalha com este tipo de informação precisa se capacitar para entender os termos e conseguir prestar o serviço que lhes é imposto com maestria.

\subsection{Principais necessidades de informação do público atendido}

No que tange às necessidades de informação do público atendido pelos bibliotecários pesquisados, segundo eles, verifica-se que há uma grande procura por informação atualizada, como afirma o bibliotecário B4: "informação pontual, exata e atualizada". Para o bibliotecário B7 “Serviço de referência e atualização da legislação." É perceptível que as pessoas sentem uma necessidade de ter a informação jurídica atualizada devido às mudanças que esta área.

Miranda, D’Amore e Pinto (2013, p. 105), afirmam que "É importante analisar, na seleção, as indicações e as sugestões dos usuários, bem como suas observações de quais áreas jurídicas encontram-se desatualizadas e escassas". Tendo esta conversa inicial com o as pessoas interessadas é possível ter uma noção do que está sendo modificado nas leis, atos normativos e doutrina, assim como o monitoramento das instituições produtoras de legislação e jurisprudência, por meio da leitura de Diário Oficial e de Diários da Justiça.

Uma das maiores necessidades é manter o acervo atualizado. Como a área do direito está sempre sendo alterada por leis e outros atos normativos, os usuários sempre vêm em busca de doutrina que contemple essas mudanças. Então, é um grande desafio, principalmente com a atual crise, manter o acervo atualizado (B8).

Ao longo da análise dos dados, observou-se que, em sua maioria $(72,22 \%$ conforme gráfico 3) os bibliotecários pesquisados atuantes em Florianópolis na área jurídica são concursados o que indica que o empreendedorismo como oportunidade de consultoria e prestação de serviços não é explorado como campo de trabalho na área de Biblioteconomia na capital do estado de Santa Catarina. Pode-se concluir que o bibliotecário jurídico pode atuar de forma autônoma e empreendedora como consultor informacional, visto que há muitas necessidades a serem supridas como, por exemplo, as dificuldades percebidas pelos profissionais que atuam na área jurídica em relação às necessidades de acesso e uso da informação. 
Pensando nos tipos de fontes de informação existentes, nas necessidades, dificuldades apontadas por bibliotecários que atuam na área jurídica em Florianópolis, foi possível atingir o objetivo geral que é analisar os serviços de informação na área jurídica que podem, potencialmente, ser prestados por meio de consultoria por bibliotecários conforme quadro 2 a seguir.

Quadro 2 - Serviços de Informação e Competências do Bibliotecário

\begin{tabular}{|c|c|}
\hline $\begin{array}{l}\text { SERVIÇO DE } \\
\text { INFORMAÇÃO }\end{array}$ & COMPETÊNCIAS NECESSÁRIAS \\
\hline $\begin{array}{l}\text { Disseminação } \\
\text { Seletiva da } \\
\text { Informação (DSI) e o } \\
\text { Serviço de } \\
\text { Referência }\end{array}$ & $\begin{array}{l}\text { Para prestação destes serviços é necessário que bibliotecário estude os } \\
\text { diferentes ramos jurídicos para poder identificar a necessidade de informação } \\
\text { de cada escritório de maneira individual, fazendo a leitura de atos normativos } \\
\text { que foram publicados nos Diários Oficiais; verificando a autenticidade das } \\
\text { fontes jurídicas disponíveis em meio virtual e repassando, assim, um } \\
\text { conteúdo de qualidade para o jurista que contratou o serviço. Poderia } \\
\text { também oferecer estes serviços de pesquisa na legislação estrangeira, } \\
\text { fazendo comparações do grau evolutivo das leis brasileiras com a de outros } \\
\text { países e enviá-las para os juristas conforme fosse solicitado. }\end{array}$ \\
\hline $\begin{array}{l}\text { Projetos internos e } \\
\text { externos, } \\
\text { capacitação } \\
\text { programas e cursos } \\
\text { de capacitação para } \\
\text { a utilização de fontes } \\
\text { de informação } \\
\text { jurídica }\end{array}$ & $\begin{array}{l}\text { O bibliotecário precisaria ter proficiência em elaboração de projetos e cursos, } \\
\text { bem como ter um conhecimento profundo sobre as fontes de informação } \\
\text { jurídica. }\end{array}$ \\
\hline Marketing Digital & $\begin{array}{l}\text { Para o bibliotecário conseguir prestar esses serviços ele deve deter o } \\
\text { conhecimento acerca de: alimentação e monitoramento de sites e redes- } \\
\text { sociais, criação de conteúdos, divulgação, comunicação e arquitetura da } \\
\text { informação e pesquisa para poder disseminar as informações especializadas } \\
\text { por meio de diferentes recursos. }\end{array}$ \\
\hline $\begin{array}{l}\text { Automação do } \\
\text { acervo/Gestão } \\
\text { Documental }\end{array}$ & $\begin{array}{l}\text { Para realizar a automação o bibliotecário deve ser conhecedor das técnicas } \\
\text { de processamento técnico, bem como saber fazer a implantação de softwares } \\
\text { e digitalização de documentos com o intuito de organizar os ambientes } \\
\text { tornando assim o acesso e recuperação da informação mais ágil. }\end{array}$ \\
\hline
\end{tabular}

Fonte: Dados da pesquisa (2019).

É importante citar que os serviços disseminação seletiva da informação, serviço de referência, elaboração de projetos internos e externos, capacitação programas e cursos de capacitação para a utilização de fontes de informação, etc. citados no Quadro 2, podem ser adaptados para outras áreas, não somente para jurídica o que amplia o leque de atuação no ramo da consultoria. Entretanto, é necessário que o bibliotecário se especialize e se mantenha em constante atualização para que as demanda encontradas sejam supridas com excelência. 


\section{Breves considerações}

Esta pesquisa foi motivada pelo interesse em ampliar e construir novos nichos de atuação para o bibliotecário no ambiente jurídico, servindo como um consultor informacional para os juristas. Para isto, foi necessário fazer uma revisão de literatura bem como a aplicação de um questionário com o intuito de obter os dados necessários para esta pesquisa.

O objetivo geral que norteou este trabalho foi levantar serviços de informação na área jurídica que podem, potencialmente, ser prestados por meio de consultoria por bibliotecários, onde foram identificados muitos serviços realizados por esses profissionais, porém não como consultoria e sim como funcionários de órgãos públicos e privados. Dentre estes, pode-se citar o Disseminação Seletiva da Informação, Serviço de Referência, Gestão documental, entre outros.

Ao mapear os serviços de consultoria informacional na área jurídica, por meio do questionário, foram identificados apenas bibliotecários que trabalham no setor público (grande maioria), alguns no setor privado e não teve nenhum que prestasse serviços de forma autônoma como consultor.

$\mathrm{Na}$ identificação de necessidades de informação na área jurídica, percebe-se que os bibliotecários respondentes conseguiram expressar quais as principais necessidades de informação que as pessoas desta área possuem. Em sua maioria, de acordo com os bibliotecários respondentes da pesquisa, a dificuldade encontrada por este público é na busca pela informação de forma ágil e pontual, bem como o acompanhamento da atualização da legislação, doutrina e jurisprudência.

Para propor serviços que possam ser ofertados por bibliotecários na área jurídica, foram identificados serviços que podem, potencialmente, ser prestados tais como: Disseminação Seletiva da Informação; o serviço de referência; organização de projetos internos e externos, capacitações, programas e cursos de capacitação para a utilização de fontes de informação jurídica e outros temas relevantes para os colaboradores que trabalham na área; marketing digital; automação e digitalização do acervo juntamente também com a gestão de documental.

\section{Referências}

ASSOCIATION OF INDEPENDENT INFORMATION PROFESSIONALS. The Independent Information Professional. Los Angeles, 2016. Disponível em: $<$ https://www.aiip.org/resources/Documents/Public/IIPWhitePaper.pdf $>$ Acesso em: 13 jun. 2019.

BAPTISTA, S. G. O. et al. O perfil do bibliotecário que atua na área jurídica: relato de pesquisa. Revista Ibero-Americana de Ciência da Informação, v. 1, n. 2, 2008. 
BAPTISTA, Sofia Galvão. Bibliotecário autônomo versus institucionalizado: carreira, mercado de trabalho e comprometimento organizacional. Tese (Doutorado em Ciência da Informação) Programa de Pós-Graduação do Departamento de Ciência da Informação e Documentação, Universidade de Brasília, Brasília, 1998.

BARROS, Lucivaldo. Fontes de informação jurídica. In: PASSOS, Edilenice (Org.). Informação Jurídica: teoria e prática. Brasília: Thesaurus, 2004.

CARDOZO, Tavita Rosa Barros; BARBOSA, Marilene Lobo Abreu. Políticas Informacionais e Práticas Pedagógicas para a formação do bibliotecário-empreendedor. In: ENCONTRO NACIONAL DE CIÊNCIA DA INFORMAÇÃO, 5., 2004, Salvador. Anais eletrônicos [...]. Salvador: UFBA, 2004.

CONTI, Daina Lindaura; PINTO, Maria Carolina Carlos; DAVOK, Delsi Fries. O perfil do bibliotecário empreendedor. Revista ACB: Biblioteconomia em Santa Catarina, Florianópolis, v. 14, n. 1, p. 27-46, jan./jun. 2009.

CONSELHO FEDERAL DE BIBLIOTECONOMIA. Resolução n. 42, de 11 de janeiro de 2002.

Disponível em: http://repositorio.cfb.org.br/bitstream/123456789/215/1/Resolucao 042-

02.pdf Acesso em: 5 jun. 2019.

COSTA, Sheila dos Santos A importância do Bibliotecário para o escritório de advocacia.

Campos Bottos. São Paulo, 9 set. 2016. Disponível em:

<http://www.camposbottos.com.br/importancia-do-bibliotecario-no-escritorio-de-

advocacia/> Acesso em: 12 jun. 2019.

DOLABELA, Fernando. 0 segredo de Luísa: uma ideia, uma paixão e um plano de negócios: como nasce o empreendedor e se cria uma empresa. São Paulo: Sextante, 2008.

DORNELAS, José Carlos Assis. Empreendedorismo corporativo: como ser empreendedor, inovar e se diferenciar na sua empresa. 2. ed. Rio de Janeiro: Campus, 2008.

DRUCKER, Peter F. Inovação e espírito empreendedor: entrepreneurship prática e princípios. São Paulo: Thomson, 1986.

FILION, Louis Jacques. Empreendedorismo: empreendedores e proprietários-gerentes de pequenos negócios. Revista de Administração, São Paulo, v. 34, n. 2, p. 5-28, abr./jun. 1999. Disponível em: http://200.232.30.99/busca/artigo.asp?num artigo=102 Acesso em: 20 abr. 2019.

MARCHIORI, P. Z. Que profissional queremos formar para o século XXI: graduação. Informação \& Informação, v. 1, n. 1, p. 27-34, jan./jun. 1996. Disponível em:

http://www.uel.br/revistas/uel/index.php/informacao/article/viewFile/1617/1371 Acesso em: 15 jun. 2019.

MENDES, Rita Rotta. Conhecimentos básicos sobre o bibliotecário jurídico: ferramentas e fontes da informação. 2010. TCC (Graduação em Biblioteconomia) - Instituto de Ciências Humanas e da Informação, Universidade Federal do Rio Grande, Rio Grande, 2010.

MILANO, Manoelle Cristine Dalri; DAVOK, Delsi Fries. Consultor de informação: serviços prestados por empresas de consultoria nas áreas de Biblioteconomia e gestão da informação.

Revista ACB, Florianópolis, v. 14, n. 1, p. 253-278, jan./jun., 2009. 
MIRANDA, Ana Claudia C.; MIRANDA, Erlano Silva de. Fontes e informação jurídica. Encontros Bibli: revista eletrônica de biblioteconomia e ciência da informação, v. 22, n.50, p. 76-90, set./dez., 2017.

MOREIRA, Fernando Cavalcanti. Bibliotecário tradicional e bibliotecário clínico: convergências para o desenvolvimento profissional. Campinas, 2008. 74 f. Monografia (Graduação em Biblioteconomia) - Faculdade de Biblioteconomia, Pontifícia Universidade Católica de Campinas, Campinas, 2008.

MOURÃO, Luciana. Oportunidades de qualificação profissional no Brasil: reflexões a partir de um panorama quantitativo. Revista Administração Contemporânea, Curitiba, v. 13, n. 1, p. 136153, Mar. 2009.

NASCIMENTO, Paola T. Oliveira do. Captação de recursos via lei Rouanet (8.313/1991) para projetos culturais no Brasil. Revista Brasileira de Biblioteconomia e Documentação, São Paulo, v. 15, n. esp., 2019. Disponível em <https://rbbd.febab.org.br/rbbd/article/view/1237/1115> Acesso em: 27 jul. 2019.

OLIVEIRA, Djalma de Pinho Rebouças de. Manual de consultoria empresarial: conceitos, metodologias e práticas. São Paulo: Atlas, 1999.

PASSOS, Edilenice. Bibliotecário jurídico: seu perfil, seu papel. Infolegis. Brasília, 2001. Disponível em: http://www.infolegis.com.br/perfilbibjridico.htm Acesso em: 20 jul. 2019.

PASSOS, Edilenice; BARROS, Lucivaldo Vasconcelos. Fontes de informação para pesquisa em direito. Brasília, DF: Lemos Informação e Comunicação, 2009.

PERILLO, A. C. Fontes de informação jurídica: avaliação do portal da Câmara dos Deputados, 2012. Monografia (Graduação em Biblioteconomia) - Faculdade de Comunicação e Biblioteconomia, Universidade Federal de Goiás, Goiânia, 2012 Disponível em: <http://repositorio.bc.ufg.br > Acesso em: 27 jul. 2019.

RACHEL, A. R. O que se entende por serviço público e quais princípios estão a ele relacionados? JusBrasil, 2009. Disponível em: http://lfg.jusbrasil.com.br/noticias/554734/o-que-se-entendepor-servico-publico-e-quais-principios-estao-a-ele-relacionados-andrea-russar-rachel Acesso em: 01 jul. 2019.

SABBAG, Paulo Yazigi. Gerenciamento de projetos e empreendedorismo. 2. ed. São Paulo: Saraiva, 2013.

SILVA, Fabiano Couto Corrêa da. Bibliotecários especialistas: guia de especialidade e recursos informacionais. Brasília: Thesaurus, 2005

SPUDEIT, Daniela (Org.). Empreendedorismo na biblioteconomia. Rio de Janeiro: Agência Biblioo, 2016a.

SPUDEIT, Daniela et al. Empresas criadas por bibliotecários no Brasil: uma análise em relação ao perfil e ramos de atuação. Revista ACB, v. 21, n. 3, p. 676-696, dez. 2016b. Disponível em: https://revista.acbsc.org.br/racb/article/view/1209 Acesso em: 21 nov. 2019. 
VALENTIM, M. L. P. Atuação e perspectivas profissionais para o profissional da informação. In: VALENTIM, M. L. P. (Org.). O profissional da informação: formação, perfil e atuação profissional. São Paulo: Polis, 2000. cap. 7, p. 135-152. 